\title{
Ciclo de Vida de Escritórios Contábeis Cadastrados no Clube dos Contadores: Uma Aplicação do Modelo de Greiner (1998)
}

\author{
Érica Daniela Morais \\ Mestrado em Administração pela Faculdade Novos Horizontes - FNH \\ Pesquisadora na Faculdade Novos Horizontes - FNH \\ Rua Alvarenga Peixoto, 1270. Santo Agostinho. Belo Horizonte/MG. CEP: 30180-121 \\ E-mail: erica.dmorais@yahoo.com.br \\ Wendel Alex Castro Silva \\ Doutorado em Administração pela Universidade Federal de Lavras - UFLA \\ Professor da Faculdade Novos Horizontes - FNH \\ Rua Alvarenga Peixoto, 1270. Santo Agostinho. Belo Horizonte/MG. CEP: 30180-121
}

E-mail: wendel.silva@unihorizontes.br

\section{RESUMO}

Este artigo tem como objetivo principal identificar em qual fase do Ciclo de Vida Organizacional (CVO) se encontra os escritórios de contabilidade existentes no cadastro do Clube dos Contadores, segundo o modelo de Greiner (1998). Para isso, realizou-se uma pesquisa descritiva, com abordagem quantitativa. Os dados foram coletados por meio de questionário estruturado composto por questões fechadas em escala Likert de cinco pontos. Dentre os 16 escritórios respondentes, que são microempresas, verificou-se que $37 \%$ deles estão na fase de Colaboração, um indicativo de maturidade no CVO, enquanto outros $31,3 \%$, estão no estágio da Criatividade, correspondente a fase de nascimento da organização. Contudo, os escritórios situados neste estágio têm mais de 10 anos de atividades, e quando se consideram aqueles que estão até o estágio de Delegação, percebe-se um falso sinal de longevidade, pois a informalidade dos processos dessas organizações pode levá-las a mortalidade. Acredita-se que os resultados desse estudo possam auxiliar os gestores desses escritórios no desenvolvimento da fase em que se encontram, contribuindo para o aperfeiçoamento de seus processos de produção de serviços, bem como para sua longevidade.

Palavras chave: Modelos de Ciclo de Vida Organizacional. Modelo de Greiner. Escritórios de Contabilidade.

Life Cycle Accounting Office registered in the Club of Accountants: An Application of Greiner Model (1998) 


\section{ABSTRACT}

This article aims to identify in what phase of Organizational Life Cycle (OLC) are the accounting firms existing in the records of the Accountants Club, on the Greiner Model (1998). For this, we carried out a descriptive research with quantitative approach. Data were collected through structured questionnaire composed of closed questions on a Likert scale of five points. Among the 16 responding firms, which are micro-enterprises, found that $37 \%$ of them are in the process of Collaboration, an indication of maturity in the OLC, while another $31,3 \%$ are at the stage of Creativity, the corresponding stage of birth the organization. However, at this stage have offices in more than 10 years of activities, and when considering those who are up to the stage of Delegation, one perceives a false sign of longevity, because the informality of the processes of these organizations can lead them to death. It is believed that this could help the managers of these offices on the development phase in which they are contributing to the improvement of their production services, and also for its longevity.

Keywords: Life Cycle. Greiner Model. Accounting Firms.

\section{INTRODUÇÃO}

O significado do termo "ciclo de vida" foi desenvolvido a princípio, no campo das ciências biológicas e fisiológicas, e tem sido aplicado em diversas áreas do conhecimento, principalmente, nas ciências sociais, uma vez que se adapta às questões referentes ao desenvolvimento das civilizações, culturas, línguas, entre outras. Sendo assim, identificam uma lógica evolutiva e relacionam mudanças e atributos específicos que caracterizam determinada unidade de análise em um determinado momento (FREITAS et al., 2002).

As organizações se assemelham aos organismos vivos, nascem, crescem, desenvolvem-se, envelhecem e morrem, caracterizando o ciclo de vida organizacional (CVO). Este enfatiza cada fase do desenvolvimento da organização, que se diferencia dos organismos vivos por não estar relacionado ao tamanho nem ao tempo de vida das mesmas, mas à flexibilidade e complexidade no controle das ações e a possíveis resistências a mudanças (ADIZES, 1990).

Bridges (1998) cita que as organizações, assim como os organismos vivos, a partir da sua criação, apresentam determinado período de vida ou de duração. A esse 
período denomina-se CVO, que começa com sua concepção e termina na velhice com a sua morte. O CVO pode ser caracterizado como um processo evolutivo de uma organização, desde sua criação até se tornar efetivamente consolidada, porém com uma série de etapas que devem ser superadas. (LEZANA; GRAPEGIA, 2006).

De acordo com Borinelli (1998), um motivo para se estudar o CVO seria a questão da transição da organização de uma fase para outra, ou seja, se a mesma possui conhecimento da fase em que se encontra. Para se desenvolver, ela tende a passar para outra fase e, com sabedoria, nessa transição não enfrentará uma crise. Assim sendo, poderá entrar em um novo estágio de vida fortalecida e amadurecida, caso contrário poderá iniciar esse novo estágio com problemas de gestão e continuidade.

O estudo do CVO fornece condições para se entender cada fase do desenvolvimento pelo qual passam as organizações, sendo que em cada fase são apresentadas características próprias e distintas (PEDRO, 2003).

Nesse contexto, a questão que norteia esta pesquisa é: Em qual fase do CVO se encontram os escritórios de contabilidade cadastrados no Clube dos Contadores, conforme o modelo de Greiner (1998).

Logo, o objetivo deste artigo é identificar em qual fase do CVO se encontram os escritórios de contabilidade, segundo a abordagem de Greiner (1998). Acredita-se que isso poderá auxiliar os gestores desses escritórios sobre o desenvolvimento da fase em que se encontram, contribuindo para o aperfeiçoamento de seus processos.

Após esta introdução, na segunda seção é desenvolvido o referencial teórico. $\mathrm{Na}$ terceira seção descreve-se a metodologia utilizada; na quarta seção são apresentados e discutidos os resultados; e, finalmente, na quinta seção são indicadas as considerações finais e a conclusão, seguidas das referências utilizadas. 
Ciclo de Vida de Escritórios Contábeis cadastrados no Clube dos contadores: Uma aplicação do Modelo de Greiner (1998) Érica Daniela Morais, Wendel Alex Castro Silva

\section{REFERENCIAL TEÓRICO}

\subsection{Modelos de Análise do Ciclo de Vida Organizacional}

Os estudos sobre o CVO vêm sendo desenvolvidos ao longo dos anos por distintos autores, em que cada qual apresenta seu modelo de forma diferenciada. São apresentadas algumas características dos modelos de CVO, iniciando pelo de Greiner (1972), Quinn e Cameron (1983), Churchill e Lewis (1983), Miller e Friesen (1984), Scott e Bruce (1987), Kaufmann (1990), Adizes (1990), Gersick (1997) e Tröger e Oliveira (1999).

Esses autores são considerados clássicos nos estudos de CVO, os quais divergem quanto às denominações das fases, das formas de análises, do número de estágios e da inclusão ou não de um estágio de pré-concepção ou outro de declínio do modelo. A variação de estágio se dá de acordo com as percepções teóricas de cada autor, de três, conforme Machado-da-Silva, Vieira e Dellagnelo (1998) a dez, como Adizes (1990). O Quadro 1 apresenta estágios, etapas ou fases de CVO segundo os autores citados. 
Ciclo de Vida de Escritórios Contábeis cadastrados no Clube dos contadores: Uma aplicação do Modelo de Greiner (1998)

Érica Daniela Morais, Wendel Alex Castro Silva

\begin{tabular}{|c|c|}
\hline Autor (es) & Estágios/Etapas/Fases \\
\hline $\begin{array}{l}\text { Greiner } \\
\text { (1972) }\end{array}$ & Criatividade, Direção, Delegação, Coordenação e Colaboração. \\
\hline $\begin{array}{l}\text { Quinn e Cameron } \\
(1983)\end{array}$ & $\begin{array}{c}\text { Empresarial, Coletividade, Formalização e Controle e Elaboração, Adaptação da } \\
\text { Estrutura. }\end{array}$ \\
\hline $\begin{array}{l}\text { Churchil e Lewis } \\
\text { (1983) }\end{array}$ & Existência, Sobrevivência, Sucesso, Decolagem e Maturidade. \\
\hline $\begin{array}{l}\text { Miller e Friesen } \\
\quad(1984)\end{array}$ & Nascimento, Crescimento, Maturidade, Renovação e Declínio. \\
\hline $\begin{array}{l}\text { Scott e Bruce } \\
\quad(1987)\end{array}$ & Início, Sobrevivência, Crescimento, Expansão e Maturidade. \\
\hline $\begin{array}{l}\text { Adizes } \\
(1990)\end{array}$ & $\begin{array}{c}\text { Namoro, Infância, Toca-Toca, Adolescência, Plenitude, Estabilidade, Aristocracia, } \\
\text { Burocracia Incipiente, Burocracia e Morte. }\end{array}$ \\
\hline $\begin{array}{l}\text { Kaufman } \\
(1990)\end{array}$ & Nascimento, Crescimento, Maturação e Institucionalização, Renovação. \\
\hline $\begin{array}{l}\text { Bridges } \\
(1993)\end{array}$ & $\begin{array}{l}\text { Sonho, Empreendimento de risco, Como conseguir organizar-se, Sucesso e como } \\
\text { transformar-se em instituição, A empresa se fecha e Morte. }\end{array}$ \\
\hline $\begin{array}{l}\text { Marques } \\
(1994)\end{array}$ & $\begin{array}{c}\text { Estágio conceptual, Estágio organizativo, Estágio produtivo, Estágio caçador, } \\
\text { Estágio administrativo, Estágio normativo, Estágio participativo, Estágio adaptativo } \\
\text { e Estágio inovativo. }\end{array}$ \\
\hline $\begin{array}{l}\text { Machado-da-Silva, } \\
\text { Vieira e Dellangelo } \\
\text { (1998) }\end{array}$ & Estágio de Empreendimento, Estágio de Formalização e Estágio de Flexibilização. \\
\hline
\end{tabular}

Quadro 1 - Estágios/Etapas/Fases do Ciclo de Vida das Organizações

Fonte: Elaborado pelos autores.

De acordo com Adizes (1990), o crescimento e o envelhecimento das organizações ocorrem em função da inter-relação entre dois fatores: flexibilidade e controlabilidade. As organizações jovens tendem a ser mais flexíveis, mas nem sempre controláveis, ao contrário das mais velhas, que são menos flexíveis e mais controláveis. $E$, ainda, tamanho e tempo não são considerados causas de crescimento e envelhecimento. Uma organização jovem é aquela que é capaz de mudar com relativa facilidade, já em uma organização velha o comportamento é mais controlável, porém pouco propensa à mudanças.

O autor ainda assinala que quando uma organização é ao mesmo tempo controlável e flexível, ela não é nem jovem nem velha demais. A mesma possui vantagens tanto da juventude quanto da maturidade e se classifica em um estágio denominado como Plenitude. Segundo Adizes (1990, p. 3), este "é o ponto mais favorável na curva do CVO, quando a organização atinge um equilíbrio de autocontrole 
e de flexibilidade". Ao atingir esse estágio a organização pode alterar sua direção e controlar o que deseja fazer.

O propósito de Adizes (1990) ao desenvolver o modelo do CVO foi estudar o que afeta essa flexibilidade e autocontrole, além de analisar como gerir esses fatores para que a organização atinja e permaneça na Plenitude.

Como todo organismo vivo uma organização passa por vários estágios de desenvolvimento. Em cada estágio ocorrem novas crises e desafios (KAUFMAN, 1990). De acordo com a habilidade de cada organização, esta avança para um novo estágio geralmente mais fortalecida. Em um estudo mais aprofundado, Kaufman (1990) define o CVO em quatro fases, como apresentado no Quadro 1. Contudo, esta pesquisa se pauta na abordagem de Greiner (1998), a qual é apresentada detalhadamente na próxima seção.

\subsection{O Modelo de Greiner (1998)}

De acordo com Greiner (1998), o futuro de uma organização é determinado mais em função da sua história do que por forças exteriores à ela. Em vista disso, ele define uma série de fases relativas ao desenvolvimento pelo qual as organizações em crescimento tendem a passar. $O$ autor ainda faz um paralelo entre o termo evolução e revolução. O primeiro refere-se aos períodos prolongados de crescimento da organização em que não ocorrem muitas movimentações ou mudanças, já o segundo seria o período de grande desordem na vida das mesmas. Ressalta ainda que dentro dos períodos de evolução das organizações ocorrem muitas revoluções, as quais são o ponto de partida para uma nova fase do CVO (Figura 1). 
Ciclo de Vida de Escritórios Contábeis cadastrados no Clube dos contadores: Uma aplicação do Modelo de Greiner (1998)

Érica Daniela Morais, Wendel Alex Castro Silva

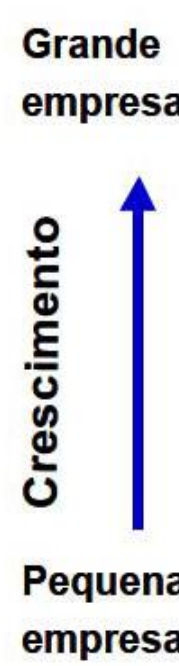

Empresa

Evolução

Jovem

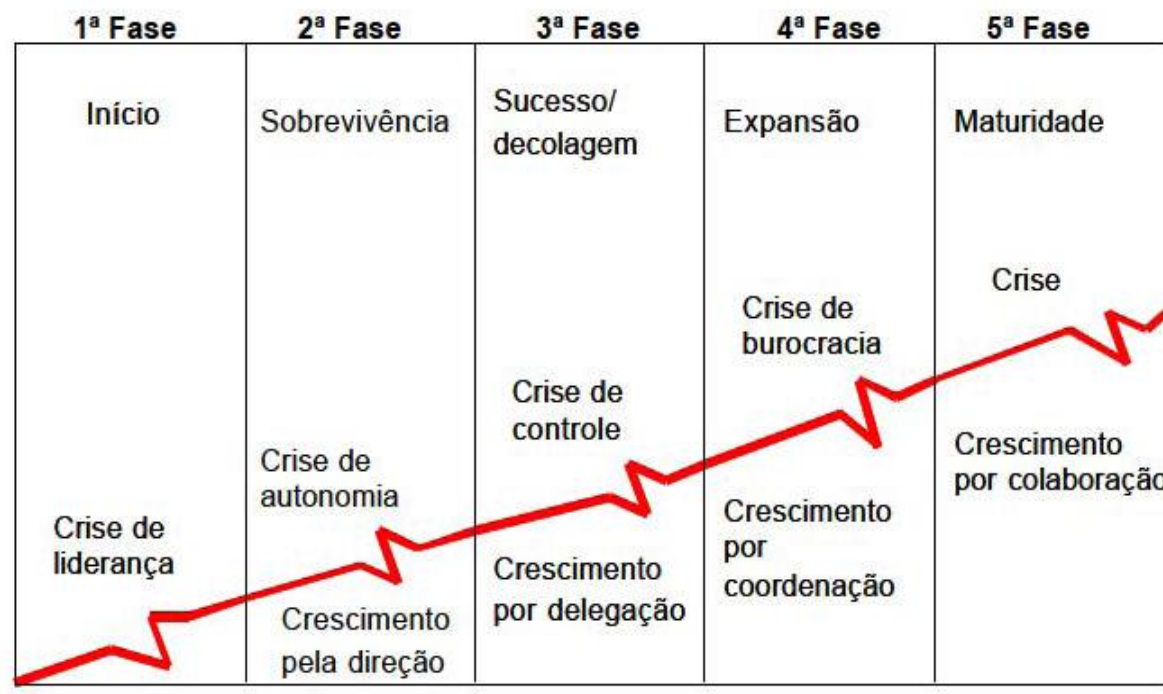

Crescimento pela

criatividade

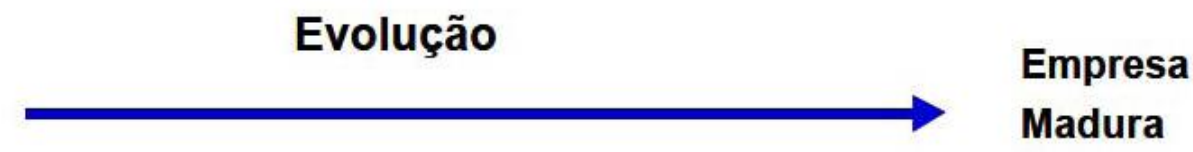

Figura 1 - Modelo de CVO de Greiner (1998).

Fonte: Pedro (2003, p. 32).

Como está apresentada na Figura 1, cada fase é um efeito da fase anterior e uma causa para a próxima fase, e cada período evolutivo é caracterizado pelo estilo de gerenciamento dominante na organização, utilizado para atingir o crescimento, enquanto que cada período revolucionário é salientado pelo problema de gerenciamento dominante que deve ser resolvido antes que o crescimento possa continuar. Abaixo são descritas as fases do modelo de Greiner (1998):

1ㄹ Fase - Criatividade: é a fase de nascimento da organização em que o foco se encontra no mercado e no produto. Caracteriza-se por longas jornadas de trabalho com salários compensadores; a comunicação entre a equipe frequentemente é informal; os fundadores exercem funções gerenciais, além de estarem voltados a produzir e vender cada vez mais o seu produto.

Crise da Liderança: a empresa cresce, as operações de produção (processos) requerem um maior conhecimento e acompanhamento sobre seu desempenho, 
aumenta o número de empregados que não podem mais ser gerenciados por meio de uma comunicação informal e muitos não estão motivados para uma dedicação intensa à organização. Os fundadores se veem oprimidos com tanta responsabilidade e os conflitos entre líderes crescem de forma intensa. Ocorre a crise da liderança, daí a necessidade de um líder de pulso forte, que tenha conhecimentos para gerenciar e habilidades para introduzir novas técnicas aos negócios.

2 Fase - Direção: após sobreviverem à primeira fase, as organizações entram no período de crescimento. Esse período de liderança hábil e diretiva apresenta as seguintes características: inicia-se uma estrutura de organização funcional para separar as atividades por área: as atividades de comercialização são separadas da produção; são introduzidos sistemas de contabilidade para estoque e compra de produtos; são adotadas novas normas de trabalho, programas de incentivo e orçamentos; a comunicação se torna informal e impessoal de acordo com a hierarquia.

Crise de Autonomia: com o crescimento a organização se torna mais complexa. Os empregados de níveis hierárquicos inferiores se veem limitados em seu poder, e mostram-se divididos entre seguir procedimentos e tomar iniciativas. Essa fase é marcada por demanda de maior autonomia por parte dos gerentes dos referidos níveis. A solução é seguir em direção a um processo de delegação de poder, iniciando um processo de descentralização.

3a Fase - Delegação: essa fase é marcada pelo processo de descentralização do poder e se caracteriza pelos seguintes pontos: aos gerentes são atribuídas maiores responsabilidades; o bônus é uma forma de benefício usado para estimular o empregado a produzir ou vender mais; a comunicação da alta gerência é desenvolvida geralmente por informes, correspondências ou telefone, uma vez que se encontra mais distante do nível operacional.

Crise do Controle: esta crise ocorre principalmente pela descentralização do poder que ocorre em função das diversidades ocorridas na organização. A alta gerência 
Ciclo de Vida de Escritórios Contábeis cadastrados no Clube dos contadores: Uma aplicação do Modelo de Greiner (1998)

Érica Daniela Morais, Wendel Alex Castro Silva

decide retomar o poder e recuperar o controle da organização. A solução seria em retomar algumas técnicas específicas de coordenação.

4므 - Fase - Coordenação: essa fase é marcada pela ascensão de sistemas formais de gerenciamento, que estimulam os gerentes a perceberem mais que as necessidades da organização e tem como principais características: planejamento formalizado com o objetivo de manter o controle da empresa; unidades descentralizadas são fundidas em grupos de produtos; funções, como processamento de dados é centralizado nos centros de operações, enquanto as decisões de operações diárias se mantêm descentralizadas.

Crise da Burocracia: os sistemas formais se tornam burocráticos em função do tamanho e da complexidade da organização.

5a Fase - Colaboração: nessa fase o controle social e a autodisciplina determinam o controle formal. É um processo de transição difícil na tentativa de superar a burocracia existente. Algumas características: as equipes são divididas em função das tarefas; utiliza-se uma estrutura do tipo matriz para designar as equipes de acordo com as tarefas; os sistemas formais são simplificados e transformados em sistemas únicos com diversas funções; os gerentes se reúnem com o objetivo de solucionar problemas maiores; novas práticas são encorajadas pela organização.

Segundo Greiner (1998), a crise nessa fase está marcada pelo stress profissional, principalmente, a sobrecarga de trabalho que será resolvida por meio de uma nova estrutura e programas que permitam aos empregados descansarem periodicamente, refletirem e se revitalizarem.

São poucas as organizações que passam por todas essas fases de crescimento. De acordo com o desenvolvimento da organização, torna-se possível observar sinais de outras fases, sejam anteriores ou posteriores à fase em que a mesma se encontra. A superação das dificuldades identificadas na evolução das organizações depende da atenção do empreendedor com os instrumentos que o meio oferece e do reconhecimento das deficiências (GREINER, 1998). 


\subsection{Trabalhos Anteriores Encontrados na Literatura Brasileira Recente}

No Quadro 2 são apresentados alguns aspectos sobre trabalhos de CVO que abordaram o modelo de Greiner (1998) no Brasil.

\begin{tabular}{|c|c|c|c|}
\hline Autor /Ano & Objetivo & Objeto & Resultados \\
\hline $\begin{array}{l}\text { Pedro } \\
\text { (2003) }\end{array}$ & $\begin{array}{l}\text { Identificar as } \\
\text { necessidades dos } \\
\text { empreendedores, } \\
\text { a importância dos } \\
\text { valores para eles e } \\
\text { averiguar as } \\
\text { influências destes no } \\
\text { empreendimento. }\end{array}$ & $\begin{array}{c}\text { Empresários } \\
\text { participantes do } \\
\text { Projeto de } \\
\text { Capacitação } \\
\text { Empresarial } \\
\text { oferecido pelo } \\
\text { Instituto Euvaldo } \\
\text { Lodi (IEL) e } \\
\text { SEBRAE }\end{array}$ & $\begin{array}{c}\text { Não foi possível verificar as tendências do } \\
\text { empreendedor nas fases de criatividade, } \\
\text { coordenação e colaboração do Modelo de } \\
\text { Greiner. Empreendedores demonstraram } \\
\text { que é possível comprovar em um caso } \\
\text { prático a associação entre as } \\
\text { características comportamentais e as fases } \\
\text { do Modelo. }\end{array}$ \\
\hline $\begin{array}{l}\text { Lezana e } \\
\text { Grapegia } \\
(2006)\end{array}$ & $\begin{array}{c}\text { Apresentar o } \\
\text { desenvolvimento e os } \\
\text { resultados da } \\
\text { aplicação do modelo } \\
\text { de Greiner (1998), } \\
\text { baseado no estilo de } \\
\text { gestão e tipo de crise } \\
\text { enfrentada. }\end{array}$ & $\begin{array}{l}\text { Proprietários de } \\
\text { organizações no } \\
\text { Arranjo Produtivo } \\
\text { Local (APL) de } \\
\text { moda e vestuário } \\
\text { de Francisco } \\
\text { Beltrão, no Estado } \\
\text { do Paraná. }\end{array}$ & $\begin{array}{l}\text { Somente um participante discordou do } \\
\text { resultado do perfil da sua empresa. Os } \\
\text { demais indicaram que o resultado refletia } \\
\text { precisamente a situação de suas } \\
\text { organizações. }\end{array}$ \\
\hline $\begin{array}{l}\text { Silva } \\
(2008)\end{array}$ & $\begin{array}{l}\text { Identificar em quais } \\
\text { fases do CVO } \\
\text { segundo o modelo de } \\
\text { Gersick (1997) e } \\
\text { Greiner (1998) se } \\
\text { concentram as } \\
\text { indústrias familiares } \\
\text { de móveis. }\end{array}$ & $\begin{array}{l}\text { Pólo Moveleiro } \\
\text { de São Bento do } \\
\text { Sul/ SC. }\end{array}$ & $\begin{array}{l}\text { Verificou-se } 22 \text { indústrias no estágio de } \\
\text { criatividade, } 13 \text { no estágio de orientação, } 9 \\
\text { no de delegação, } 4 \text { no coordenação e } 2 \text { no } \\
\text { estágio de colaboração. Essa maior } \\
\text { concentração no estágio de criatividade é } \\
\text { comum nas empresas de gestão informal. } \\
\text { Quanto a essa simetria entre controles de } \\
\text { gestão e o CVO das indústrias, pôde ser } \\
\text { visto uma menor utilização dos controles } \\
\text { no primeiro estágio, aumentando } \\
\text { gradativamente no segundo, terceiro e } \\
\text { quarto, respectivamente, no quinto houve } \\
\text { uma queda na utilização de controles } \\
\text { devido à necessidade de reorganização do } \\
\text { sistema de controle. }\end{array}$ \\
\hline
\end{tabular}

Quadro 2 - Trabalhos anteriores que aplicaram o modelo de Greiner (1998)

Fonte: Elaborado pelos autores.

Pode-se perceber que dentre as pesquisas implementadas para estudar o CVO encontradas na literatura, o foco se deu naquelas da área de moda e vestuário, móveis, em que se situaram, sobremaneira, no estágio de criatividade. Além de não identificar pesquisas que analisaram o CVO de escritórios de contabilidade, o que reforça 0 
Ciclo de Vida de Escritórios Contábeis cadastrados no Clube dos contadores: Uma aplicação do Modelo de Greiner (1998)

Érica Daniela Morais, Wendel Alex Castro Silva

interesse por investigá-los neste trabalho, nota que são casos restritamente específicos cujo resultado não faz interseção um com o outro.

\section{METODOLOGIA}

Trata-se de uma pesquisa descritiva, pois tem o intuito de descrever fenômenos, levantando as características de uma determinada população procurando o estabelecimento das relações entre as variáveis (LAKATOS, 2002; GIL, 2002). Assim, o objetivo central deste artigo é identificar em qual fase do CVO se encontram os escritórios de contabilidade cadastrados no Clube dos Contadores, tendo como referência a abordagem de Greiner (1998).

Esta pesquisa apresenta natureza aplicada, a qual busca gerar conhecimentos para a aplicação prática, na solução de problemas que ocorrem na realidade. A forma de abordagem do problema é quantitativa, sendo que o seu grande valor é trazer a teoria para a realidade (MICHEL, 2005). Centra-se na quantificação de fenômenos, por meio da coleta e análise de dados numéricos, com a utilização de testes estatísticos (COLLIS; HUSSEY, 2005). As unidades de análise foram escritórios de contabilidade cadastrados no Clube dos Contadores e as unidades de observação foram os seus respondentes do questionário.

A população da pesquisa refere-se a todos os escritórios de contabilidade cadastrados no Clube dos Contadores, o qual possui associados em vários estados do Brasil. A amostra do estudo compreende a quantidade de escritórios cujos gestores responderam as questões que Ihes foram encaminhadas, significando 16 escritórios, pois grande parte das organizações contatadas não mostrou interesse em contribuir para a pesquisa, por meio de seus proprietários e/ou gestores.

No que tange a coleta de dados foi disponibilizado um link na internet (no qual estava inserido o questionário) para os escritórios que se encontravam cadastrados na base de dados do Clube dos Contadores. Utilizou-se como técnica de coleta um questionário estruturado composto por questões fechadas em escala Likert de cinco pontos. As categorias tinham uma escala que variava de 1 a 5 opções, em que 1 
significa que o respondente discordava totalmente com o item apresentado e 5 se ele concordava totalmente. Foi replicado parte do questionário de Silva (2008), o qual foi elaborado a partir de questões teóricas fundamentadas no modelo conceitual do CVO a partir da abordagem de Greiner (1998). Esse questionário era composto por 30 perguntas, sendo divididos em cinco grupos referentes aos estágios de classificação da organização, segundo o modelo CVO de Greiner (1998) - descrito na seção 2.2 - tendo cada grupo 6 perguntas. Para cada afirmação os respondentes deveriam atribuir à opção de resposta que percebiam ser adequada à organização. A cada item eles apontavam se discordavam totalmente, discordavam, concordavam parcialmente, concordavam ou concordavam totalmente.

O próximo passo consistiu no tratamento estatístico dos dados obtidos. Após a categorização dos mesmos foi calculada uma média para cada respondente acerca de cada um dos cinco grupos e, posteriormente, esta média foi padronizada. Esta medida foi escolhida por levar em consideração uma comparação do valor médio encontrado para o indivíduo i para cada grupo j (médiaii) e da média e desvio padrão geral (médiaij e desvio padrãoij, respectivamente para cada grupo. Assim, o cálculo realizado foi:

$$
\text { Escore }_{i j}=\frac{\text { Média }_{i j}-\text { Média }_{j}}{\text { Desvio padrão }_{j}}
$$

Em que: $i$ é o respondente, variando de 1 a 16

[Equação 1]

jé o grupo, variando de 1 a 5.

Depois da atribuição dos escores, cada respondente possuía um valor para cada um dos grupos. O grupo de classificação foi então definido como o grupo cujo escore do respondente foi o maior valor entre os 5 grupos. Assim, foi atribuída a cada respondente a classificação da fase do CVO em que sua empresa se encontra. 
Ciclo de Vida de Escritórios Contábeis cadastrados no Clube dos contadores: Uma aplicação do Modelo de Greiner (1998)

Érica Daniela Morais, Wendel Alex Castro Silva

\section{ANÁLISE E DISCUSSÃO DOS DADOS}

A partir das informações levantadas junto aos escritórios, desenvolveu-se uma análise utilizando-se algumas características dos mesmos, a partir do Modelo de Greiner (1998).

\subsection{Caracterização dos escritórios contábeis}

Nesta seção são descritos alguns aspectos que caracterizam a amostra de escritórios estudados.

Tabela 1 - Estado de localização da empresa

\begin{tabular}{|c|c|c|c|}
\hline & No empresas & \% & \% acumulado \\
\hline Minas Gerais & 8 & $\mathbf{5 0 , 0}$ & 50,0 \\
\hline Distrito Federal & 2 & 12,5 & 62,5 \\
\hline Paraná & 1 & 6,3 & 68,8 \\
\hline Acre & 1 & 6,3 & 75,1 \\
\hline São Paulo & 1 & 6,3 & 81,4 \\
\hline Rio Grande do Sul & 1 & 6,3 & 87,7 \\
\hline Não respondeu & 2 & 12,3 & 100,0 \\
\hline Total & $\mathbf{1 6}$ & $\mathbf{1 0 0 , 0}$ & \\
\hline
\end{tabular}

Fonte: dados da pesquisa.

Em relação à localização dos escritórios respondentes, 50\% estão situados no estado de Minas Gerais. O restante distribuiu-se no Distrito Federal, Paraná, Acre, São Paulo e Rio Grande do Sul, conforme consta na Tabela 1. Observa-se que 56,3\% desses escritórios localizam-se na região sudeste. 
Ciclo de Vida de Escritórios Contábeis cadastrados no Clube dos contadores: Uma aplicação do Modelo de Greiner (1998) Érica Daniela Morais, Wendel Alex Castro Silva

Tabela 2 - Tempo de fundação da empresa

\begin{tabular}{|c|c|c|c|}
\hline & № empresas & $\%$ & \% acumulado \\
\hline 0 a 5 anos & 1 & 6,3 & 6,3 \\
\hline 6 a 10 anos & 1 & 6,3 & 12,6 \\
\hline 11 a 15 anos & 4 & $\mathbf{2 5 , 0}$ & 37,6 \\
\hline 16 a 20 anos & 3 & 18,8 & 58,4 \\
\hline 21 a 25 anos & 2 & 12,5 & 68,9 \\
\hline 26 anos ou mais & 4 & $\mathbf{2 5 , 0}$ & 93.9 \\
\hline Não respondeu & 1 & 6,1 & 100,0 \\
\hline Total & $\mathbf{1 6}$ & $\mathbf{1 0 0 , 0}$ & \\
\hline
\end{tabular}

Fonte: dados da pesquisa.

De acordo com a Tabela 2, em relação ao tempo de fundação dos escritórios, $25 \%$ dos respondentes tem entre 11 e 15 anos de fundação, e outros $25 \%$ tem 26 anos ou mais de fundação, sendo os percentuais mais representativos. Logo, em média, indicaram possuir mais de 10 anos de funcionamento. Apenas $12,6 \%$ dos respondentes possuem 10 anos ou menos de fundação.

Tabela 3 - Número de funcionários da empresa

\begin{tabular}{|c|c|c|c|}
\hline & No empresas & $\%$ & \% acumulado \\
\hline Até 5 & 7 & $\mathbf{4 3 , 8}$ & 43,8 \\
\hline 6 a 10 & 3 & 18,8 & 62,6 \\
\hline 11 a 15 & 3 & 18,8 & 81,4 \\
\hline 16 a 20 & 0 & 0,0 & 81,4 \\
\hline Mais de 20 & 2 & 12,5 & 93,9 \\
\hline Não respondeu & 1 & 6,1 & 100,0 \\
\hline Total & $\mathbf{1 6}$ & $\mathbf{1 0 0 , 0}$ & \\
\hline
\end{tabular}

Fonte: dados da pesquisa.

Em relação ao número de funcionários, segundo a Tabela 3, a maior parte dos escritórios possui até 15 funcionários $(81,4 \%)$, com destaque para aqueles com até 5 funcionários, o que representa $43,8 \%$ dos respondentes. Apesar de os escritórios em estudo apresentarem longo período de fundação, o número de funcionários é pequeno, o que é uma característica comum nos escritórios desta atividade. E, como critério de 
determinação do porte da empresa, o SEBRAE (2009) define que microempresa é a que possui até dezenove pessoas ocupadas, baseando-se na quantidade de funcionários. Dessa maneira, $81 \%$ dos escritórios analisados se enquadram como microempresa.

\subsection{Classificação dos escritórios contábeis segundo o CVO}

A classificação dos escritórios com base no modelo de Greiner (1998) é mostrada a seguir.

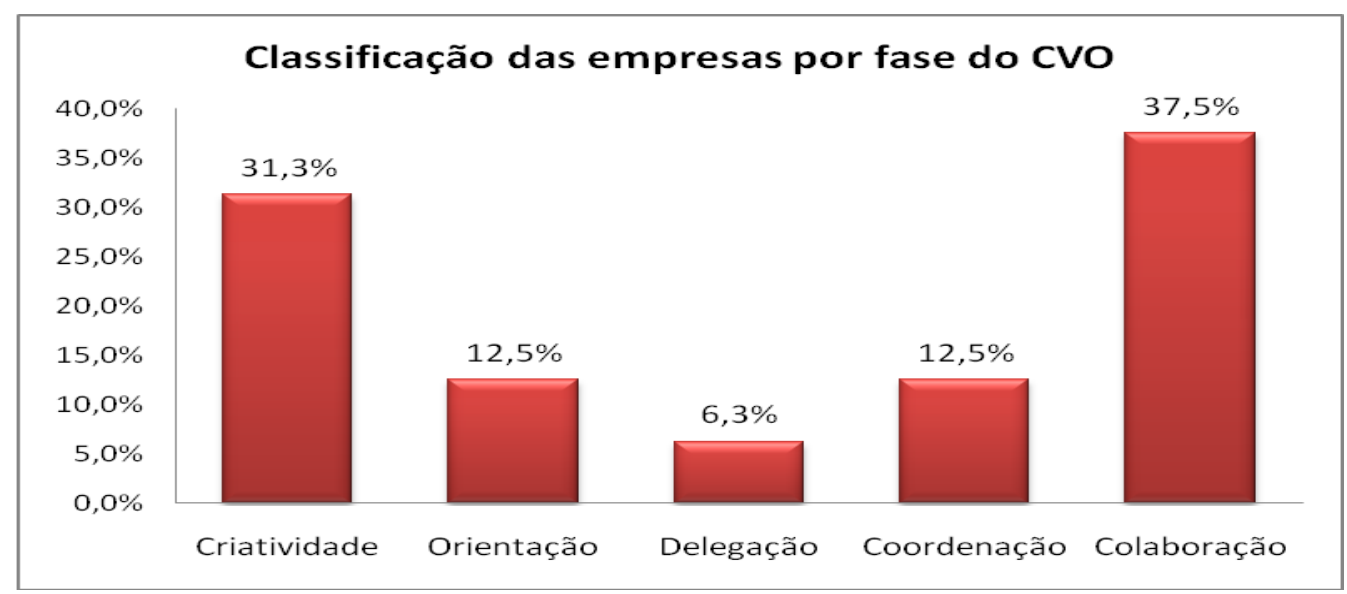

Figura 2 - Classificação das empresas de acordo com a fase do CVO Fonte: dados da pesquisa.

Percebe-se que pouco mais de $37 \%$ dos escritórios de contabilidade estão na fase de Colaboração, considerada a de maior maturidade (longevas) no CVO, em que o crescimento da organização se dá por colaboração entre seus profissionais. Nesta, conforme Greiner (1998) ocorre um período de transição difícil, com muito stress entre os profissionais, já que ocorre sobrecarga de trabalho, a qual poderá ser superada estabelecendo-se uma nova estrutura organizacional, além de haver cuidados com os recursos humanos, para permitir sua recuperação física e mental. Este estágio é caracterizado por equipes divididas em função das tarefas; a utilização de uma estrutura do tipo matriz para designar essas equipes; os sistemas formais são 
Ciclo de Vida de Escritórios Contábeis cadastrados no Clube dos contadores: Uma aplicação do Modelo de Greiner (1998)

Érica Daniela Morais, Wendel Alex Castro Silva

simplificados; os gestores procuram resolver problemas maiores e organização vislumbra novas práticas de gestão.

Também, outra importante parcela dos escritórios $(31,3 \%)$ situa-se no estágio da Criatividade, o qual ocorre no início ou nascimento da organização e a mesma está centrada no mercado e no produto. Tal estágio apresenta jornadas de trabalho extensas com remuneração compensadora; a comunicação entre o grupo é informal; os sócios exercem funções gerenciais e estão orientados para aumentar a produção de seu produto e ampliar as vendas. Para Greiner (1998), nesta etapa a organização está crescendo e estruturando seus processos, os quais demandam atenção especial e monitoramento de seu desempenho. Acontece ampliação na contratação de empregados, os quais precisam de gerenciamento por meio de uma comunicação informal, mas boa parte deles não se mostra motivada a se empenhar intensamente à organização. Nesse contexto, os gestores sofrem pressão com 0 aumento de responsabilidades, fomentando os conflitos entre líderes, gerando a necessidade de um líder capaz de conduzir o processo de evolução da organização, com a utilização técnicas de gestão inovadoras.

Então, enquanto boa parte dos escritórios apresenta-se em uma fase de estabilidade de suas operações, outra parcela pode estar passando por um momento de fortes crises em sua estrutura organizacional, demandando maior cuidado com a estruturação de seus processos, a fim de assegurar a continuidade da empresa.

Tabela 4 - Classificação CVO segundo o período de fundação da empresa

\begin{tabular}{|l|l|l|l|l|l|}
\hline & Criatividade & Orientação & Delegação & Coordenação & Colaboração \\
\hline 0 a 5 anos & & & & $1(50 \%)$ & \\
\hline 6 a 10 anos & & & & & $1(16,7 \%)$ \\
\hline 11 a 15 anos & $2(40 \%)$ & & & & $2(33,3 \%)$ \\
\hline 16 a 20 anos & $1(20 \%)$ & & $1(100 \%)$ & $1(50 \%)$ & \\
\hline 21 a 25 anos & & & & & $2(33,3 \%)$ \\
\hline 26 anos ou mais & $2(40 \%)$ & $1(50 \%)$ & & & $1(16,7 \%)$ \\
\hline Não respondeu & & $1(50 \%)$ & & & \\
\hline Total & $\mathbf{5 ( 1 0 0 \% )}$ & $\mathbf{2 ( 1 0 0 \% )}$ & $\mathbf{1 ( 1 0 0 \% )}$ & $\mathbf{2 ( 1 0 0 \% )}$ & $\mathbf{6 ( 1 0 0 \% )}$ \\
\hline
\end{tabular}

Fonte: dados da pesquisa. 
Conforme pode ser percebido na Tabela 4, os escritórios que se situam na fase de criatividade apresentam mais de 10 anos de funcionamento e, ainda, encontram-se no estágio inicial de desenvolvimento do seu CVO, o que é até certo ponto preocupante. Cerca de $50 \%$ desses escritórios situam-se até a fase intermediária de delegação. Apesar dos sinais de longevidade dessas organizações, após uma década ou mais de funcionamento seus processos ou operações se mostram bastante informais e desestruturados, sugerindo organizações instáveis, com ambientes de trabalho desorganizados e não consolidados, o que pode estar afetando a produtividade de seus funcionários, bem como a qualidade de prestação de seus serviços. Ainda assim, são fatores que podem levar a mortalidade desses escritórios em curto prazo. Por outro lado, visualizou-se que a maior parte dessas organizações são microempresas, as quais são caracterizadas pelos processos informais, baixo profissionalismo, além de seus sócios serem responsáveis pela gestão e por parcela de execução da atividade operacional.

\section{CONSIDERAÇÕES FINAIS}

O objetivo desse trabalho foi identificar a fase do CVO em que se encontram os escritórios de contabilidade cadastrados no Clube dos Contadores, segundo a abordagem de Greiner (1998).

Os dados obtidos revelam que a metade dos escritórios amostrados está situada em Minas Gerais e pouco mais da metade se localiza na região sudeste. Em termos de tempo de fundação, 25\% têm entre 11 e 15 anos de funcionamento e outros $25 \%$ tem 26 anos ou mais de atividades. A maioria conta com até quinze funcionários, metade dos quais possui até cinco funcionários, o que faz com que a maior dessas organizações se enquadre como microempresa.

Em relação ao estágio de CVO dos escritórios investigados, pouco mais de $37 \%$ deles estão na fase de Colaboração, representativa do estágio máximo de maturidade no CVO, um período de difícil transição, caracterizado pelo stress entre os membros da organização. Já outros $31,3 \%$ dos escritórios situam-se no estágio da Criatividade, no 
qual ocorre o nascimento da organização e a mesma está focada no crescimento da participação no mercado, sem muita preocupação com a formalização da estrutura.

Um resultado até certo ponto surpreendente é que os escritórios que se encontram no estágio inicial do CVO têm mais de 10 anos de funcionamento, e a situação se agrava quando se consideram aqueles situados até o estágio de delegação, perfazendo em torno da metade da amostra, o que é característico de microempresas. Ao mesmo tempo em que esses escritórios dão indícios de longevidade, apresentam aspectos de organizações bastante informais, sem padronização de processos, o que pode levar a operações de baixa qualidade, seja no ambiente interno ou externo, o que influencia na qualidade dos serviços prestados aos clientes.

Apesar de estarem sobrevivendo as mudanças intensas que tem ocorrido no ambiente das organizações nas últimas décadas, os escritórios que fazem parte da amostra do estudo estão há muitos anos em um mesmo estágio do CVO e não conseguiram ou não desejam evoluir para o estágio seguinte, deixando de alcançar um estágio de maturidade, em que a organização se apresenta estruturada adequadamente para reagir de forma positiva às mudanças e ao crescimento do mercado brasileiro. Os seus gestores precisam perceber as implicações dessa estagnação no crescimento da organização ou da recusa à sua evolução para uma organização mais formal, pois diante de tal situação podem estar seguindo para a mortalidade em um prazo relativamente curto.

Em relação às limitações desta pesquisa, considera-se a dificuldade de obtenção dos dados, o que influenciou na amostra tornando-a bastante reduzida, diante da população de escritórios que constam no cadastro do Clube de Contadores. Sugere-se que este tipo de pesquisa seja realizada em outros setores, buscando-se estabelecer comparações por meio da adoção de outros modelos de CVO.

\section{REFERÊNCIAS}

ADIZES, I. (1990). Os ciclos de vida das organizações: como e porque as empresas crescem e morrem e o que fazer a respeito. São Paulo, Pioneira, 379 p. 
Ciclo de Vida de Escritórios Contábeis cadastrados no Clube dos contadores: Uma aplicação do Modelo de Greiner (1998)

Érica Daniela Morais, Wendel Alex Castro Silva

BRIDGES, W. (1998). As empresas também precisam de terapia: como usar os tipos junguianos para o desenvolvimento organizacional. São Paulo, Editora Gente, 174 p.

BORINELLI, M. L. (1998). A identificação do ciclo de vida das pequenas empresas através das demonstrações contábeis. Florianópolis, SC. (Dissertação de mestrado). Universidade Federal de Santa Catarina - UFSC.

CHURCHILL, N. C.; LEWIS, V. L. (1983). Growing concerns: topics of particular interest to owners and managers of smaller businesses. Harvard Business Review, Watertown, p. 30-50.

COLLIS, J.; HUSSEY, R. (2005). Pesquisa em administração: um guia prático para alunos de graduação e pós-graduação. Porto Alegre, Bookman, 349 p.

FREITAS, A. F. F; COSTA, F. J.; BARROSO, H. C. M. P. (2002). Ciclo de vida organizacional: um estudo no setor de supermercados. In: Encontro Nacional da Associação Nacional dos Programas de Pós Graduação em Administração EnANPAD, 26, Salvador. Anais... Rio de Janeiro: ANPAD, p. 1-12.

GIL, A. C. (2002). Como elaborar projetos de pesquisa. São Paulo, Atlas, 175 p.

GREINER, L. E. (1972). Evolution and revolution as organizations grow. Harvard Business Review, Watertown, 50(4), p. 37-46.

GREINER, L. E. (1998). Evolution and revolution as organizations grow. Harvard Business Review. May./June., p.55-67.

KAUFMANN, L. (1990). Passaporte para o ano 2000: como desenvolver e explorar a capacidade empreendedora para crescer com sucesso até o ano 2000. São Paulo, Makron, $172 \mathrm{p}$.

LAKATOS, E. M., MARCONI, M. A. (2002). Metodologia Cientifica. São Paulo, Atlas.

LEZANA, Á. G. R.; GRAPEGIA, M. (2006). Diagnóstico da fase do ciclo de vida organizacional. Universidade Federal de Santa Catarina, Revista Produção On-line, 10(10).

MACHADO-DA-SILVA, C. L.; DELLAGNELO, E. H. L. VIEIRA, M. M. F. (1998). Tecnologia e ciclo de vida organizacional: um quadro de análise. In: Encontro Nacional da Associação Nacional dos Programas de Pós-graduação em Administração EnANPAD, 16, Canela. Anais... Rio de Janeiro, ANPAD, 1998. 
Ciclo de Vida de Escritórios Contábeis cadastrados no Clube dos contadores: Uma aplicação do Modelo de Greiner (1998)

Érica Daniela Morais, Wendel Alex Castro Silva

MARQUES, A. C. F. (1994). Deterioração organizacional: como detectar e resolver problemas de deterioração e obsolência organizacional. São Paulo, Makron Books, 203 p.

MICHEL, M. H. (2005). Metodologia de pesquisa cientifica em ciências sociais: um guia prático para acompanhamento da disciplina de elaboração de trabalhos monográficos. São Paulo, Atlas, 138 p.

MILLER, D.; FRIESEN, P. (1984). A longitudinal study of corporate life cycle. Management Science, Hanover, 0(10), p. 1161-1183.

PEDRO, A. M. (2003). Características comportamentais dos empreendedores no modelo de ciclo de vida das organizações de Greiner. $112 \mathrm{f}$.

SILVA, L. C. (2008). Controles de gestão utilizados nas fases do ciclo de vida das indústrias familiares do pólo moveleiro de São Bento do Sul, SC. 208 f. (Dissertação de mestrado). Universidade Regional de Blumenau - FURB.

SEBRAE. Ponto de Partida. Belo Horizonte: SEBRAE/MG, 01 agosto 2009. Disponível em www.sebraemg.com.br. Acesso em: 02/abr/2010.

SCOTT, M.; BRUCE, R. (1987). Five stages of growth in small business. Long Range Planning, London, 20(3), p. 45-53.

TRÖGER, A.; OLIVEIRA, J. P. M. (1999). Um modelo de ciclo de vida para organizações virtuais. In: Encontro da Associação Nacional de Programas de PósGraduação em Administração e Pesquisa em Administração - ENANPAD, 22, Foz do Iguaçu. Anais... Rio de Janeiro: ANPAD. 1 CD ROM.

NOTA DE AGRADECIMENTO

Os autores do artigo agradecem à Fundação de Amparo à Pesquisa do Estado de Minas Gerais (FAPEMIG) pelo apoio financeiro à mesma e ao Clube dos Contadores pelo apoio na pesquisa junto aos escritórios contábeis.

Data de Submissão: 19/04/2011

Data de Aceite: 18/07/2012 